\title{
PENGEMBANGAN PENDIDIKAN KARAKTER DALAM KURIKULUM PENDIDIKAN ANAK USIA DINI
}

\author{
Leli Halimah ${ }^{1}$
}

\begin{abstract}
ABSTRAK
Esensi pendidikan adalah membangun karakter anak. Untuk itu, pemerintah dalam hal ini Permendiknas (2012) telah menetapkan lima belas nilai karakter yang harus ditanamkan pada anak, sejak pendidikan usia dini. Tujuan penelitian ini, untuk mengidentifikasi nilai- nalai karakter apa yang pada umumnya secara eksplisit dirancang dalam dokumen kurikulum khususnya dalam Rencana Pelaksanaan Pembelajaran Harian (RPPH) yang disusun oleh guru anak usia dini. Metode penelitian yang digunakan yaitu metode penelitian kualitatif, dengan teknik pengumpulan data melalui studi dokumenter, dan studi literature dari situssitus di internet. Hasil studi, menyimpulkan bahwa guru pendidikan anak usia dini dalam menentukan nilai-nilai karakter untuk satu kali pertemuan pada umumnya secara eksplisit meliputi beberapa nilai karakter yang secara bervariasi paling sedikit tiga nilai karakter dan paling banyak sampai delapan nilai karakter. Hal ini sangat berbeda dengan hasil studi literature dari situs di internet yang menggambarkan bahwa untuk satu nilai karakter dikembangkan secara berkelanjutan, konsisten sampai target selama satu bulan atau sampai nilai karakter tersebut telah membudaya pada diri anak.
\end{abstract}

Kata Kunci: Pendidikan karakter dan kurikulum pendidikan anak usia dini

\section{A. PENDAhuluan}

Pendidikan anak usia dini, merupakan pendidikan yang sangat fundamental, sangat krusial dan kritis bagi keberlangsungan perkembangan anak di kemudian harinya. Orang tua, pendidik, masyarakat dan pemerintah sangat berharap program anak usia dini berkualitas, mengutamakan pendidikan karakter yang berkualitas sesuai dengan kebutuhan perkembangan anak. Menurut Hooks, dkk. (2006) program pendidikan anak usia dini yang berkualitas memiliki dampak positif pada kehidupan anak, dapat mempersiapkan anak-anak untuk sukses di sekolah dan memiliki manfaat luar biasa untuk menjadikan individu dewasa`yang baik dikemudian hari.

Di era globalisasi seperti saat ini, pendidikan karakter pada dasarnya sudah merupakan keharusan, mengingat dunia semakin kompleks, informasi dan teknologi begitu berlipah. Dampaknya pada anak-anak dari pengaruh TV, komputer, internet, lirik musik dan video, media cetak, dan juga pengaruh pergaulan dengan teman, banyak yang positifnya di samping itu banyak pula dampak negatifnya. Dalam menyikapi kondisi tersebut, anak-anak sejak dini harus dilindungi, salah satunya yaitu melalui program pendidikan karakter yang mampu memberikan filter yang kuat pada mereka. Untuk itu pendidikan karakter

\footnotetext{
${ }^{1}$ Dosen Kampus UPI Cibiru
} 
di sekolah tidak dapat diabaikan. Terlepas dari bagaimana pelaksanaan proses belajar-mengajar di ruang kelas, sekolah sebagai pihak yang berwenang memiliki peran penting dalam membentuk karakter anak. Alasannya, anak menghabiskan rata-rata sembilan sampai sepuluh jam di sekolah dari hari Senin sampai Jumat dan kadang-kadang beberapa jam pada hari Sabtu (Adeyemi., Moumakwa., \& Adeyemi., 2009).

Menurut McElmeel (2002) pada abad ke 21 yang dikenal era globalisasi ini "character education is indeed a high priority". Selain itu, pentingnya pendidikan karakter, menurut Dimerman (2009) character is the foundation to all our relationships: working, learning, loving, community, and more. Sekaitan dengan pentingnya pendidikan karakter, sangat erat kaitannya dengan kurikulum, alasannya "curriculum is the heart of education" (Null, 2011) Untuk itu, idealnya nilai-nilai karakter dan bagaimana cara-cara menanamkan nilai-nilai karakter tersebut secara eksplisit dituangkan dalam dokumen kurikulum yang akan digunakan sebagai pedoman dalam pelaksanaan pendidikan. Rich (2008) mengemukakan untuk membangun karakter yang unggul pada anak-anak sejak dini agar mereka siap dan sukses menghadapi berbagai tantangan zaman termasuk untuk mempersiapkan anak pada era teknologi dan informasi seperti saat ini dan yang akan datang, maka sangat penting kurikulum mengakomodasi "megaskills".

Pendidikan karakter menjadi semakin penting dan strategis, terutama jika dikaitkan dengan tantangan yang dihadapi oleh Indonesia dalam menyiapkan generasi masa depan dalam menghadapi tantangan global dengan permasalahan yang semakin berat dan kompleks. Untuk menghadapi tantangan di era global tersebut, diperlukan sumber daya manusia yang berpengetahuan, berketerampilan, dan berkarakter kuat (Kemdiknas, 2012; Priyatni, 2013).

\section{Pendidikan Karakter Untuk Anak Usia Dini}

Karakter berkaitan dengan hal-hal yang benar (Lickona, 2004). Karakter adalah tabiat atau kebiasaan untuk melakukan hal yang baik (Kemendiknas, 2012). Pendidikan karakter adalah upaya penanaman nilai-nilai karakter kepada anak didik, agar anak menjadi manusia yang berakhlak (Kemendiknas, 2010; Kemendiknas, 2012). Kemendiknas (2010) mengemukakan bahwa pendidikan karakter sebenarnya bukan hal yang baru. Sejak awal kemerdekaan, masa orde lama, masa orde baru, dan masa reformasi sudah dilakukan dengan nama dan bentuk yang berbeda-beda. Hal tersebut, sejalan dengan yang dikemukakan Dimerman (2009) bahwa sejak zaman dahulu, orang percaya bahwa yang harus dipelajari oleh anak-anak di sekolah adalah karakter yang baik, termasuk nilainilai moral apa yang harus terapkan dalam kehidupannya, dan tentang apa yang benar dan salah dan bagaimana anak-anak harus berperilaku.

Alasannya, menurut Stevenson (2006) bahwa karakter akan mempengaruhi cara hidup yang berkaitan dengan pilihan yang baik dan tindakan positif atau tindakan yang benar. Karakter menunjukkan dirinya dalam perilaku dan melibatkan hati nurani, menyentuh penilaian, dan pemikiran setiap individu. Lebih lanjut Stevenson (2006) mengemukakan sebanyak 50 nilai-nilai karakter yang dapat ditumbuhkembangkan pada anak-anak melalui berbagai cara yang 
kondusif. Sementara Rich (2008) mengemukakan terdapat 12 nilai karakter yang dapat mendukung anak untuk sukses pada era globalisasi yang dikenal dengan megaskills.. Kemendiknas (2010), menetapkan 18 nilai karakter, yaitu: (1) religius, (2) jujur, (3) toleransi, (4) disiplin, (5) kerja keras, (6) kreatif, (7) mandiri, (8) demokratis, (9) rasa ingin tahu, (10) semangat kebangsaan, (11) cinta tanah air, (12) menghargai prestasi, (13) bersahabat/komunikatif, (14) cinta damai, (15) gemar membaca, (16) peduli lingkungan, (17) peduli sosial, (18) tanggungjawab. Sementara dalam Kemendiknas (2012) mengemukakan nilai-nilai pendidikan karakter yang dapat ditanamkan pada anak usia dini (0-6 tahun), mencakup empat aspek, yaitu: (1) Aspek Spiritual, (2) Aspek Personal/kepribadian, (3) Aspek Sosial, dan (4) Aspek lingkungan. Semuanya itu dijabarkan ke dalam 15 nilai karakter yang akan diterapkan pada anak usia dini, yaitu: (1) kecintaan terhadap Tuhan YME; (2) kejujuran; (3) disiplin; (4) toleransi dan cinta damai; (5) percaya diri; (6) mandiri; (7) tolong menolong, kerjasama, dan gotong royong; (8) hormat dan sopan santun; (9) tanggung jawab; (10) kerja keras; (11) kepemimpinan dan keadilan; (12) kreatif; (13) rendah hati; (14) peduli lingkungan; (15) cinta bangsa dan tanah air.

Jika pemerintah telah menetapkan nilai-nilai karakter sebagaimana dikemukakan di atas, itu artinya nilai-nilai karakter tersebut harus menjadi bagian integral dari kurikulum dan pembelajaran. Hal ini sejalan dengan yang dikemukakan Adeyemi., Moumakwa., \& Adeyemi., (2009) bahwa pendidikan karakter harus menjadi bagian dari kurikulum dan selalu ditanamkan di seluruh divisi subjek mater atau lintas kurikulum.Maksudnya bahwa nilai-nilai karakter yang akan ditanamkan kepada peserta didik tersebut, tentunya harus secara eksplisist dituangkan dalam dokumen kurikulum, baik dokumen kurikulum sekolah (dokumen 1) maupun dokumen kurikulum yang dikembangkan oleh guru (dokumen 2) yang meliputi program tahunan, semester, mingguan, dan harian. Selanjutnya dokumen tersebut dijadikan pedoman dalam pelaksanaan kurikulum. Itu artinya bahwa konten kurikulum adalah nilai-nilai karakter. Karakter yang baik berkenaan dengan kebajikan (virtue). Virtue-such as honesty,justice,courage, and compassion-are dispositions to behave in a morally good way (Lickona, 2004: 7).

\section{Pelaksanaan Pendidikan Karakter}

Pelaksanaan pendidikan karakter di Indonesia masih bersifat indoktrinasi yang cenderung mengajarkan nilai. Idealnya pendidikan karakter diinternalisasi, maksudnya mengupayakan agar nilai-nilai moral menjadi milik anak, menyatu, menjadi bagian yang tidak terpisahkan dari perilaku anak dalam kehidupan baik saat ini maupun di masa mendatang. Dalam internalisasi nilai, tugas guru adalah mendorong anak untuk menjadi pemilik nilai-nilai, mengupayakan agar nilai-nilai karakter itu akan melekat kuat dalam diri anak. Hal itu akan terwujud, jika nilai-nilai itu diikat dengan pengalaman, emosi, dan motivasi personal Rich, 2002; Sudrajat, 2011 (Priyatni, 2013).

Pelaksanaan pendidikan karakter bagi anak usia dini dapat dilakukan melalui kegiatan yang terprogram dan pembiasaan. Kkususnya dalam kegiatan 
terprogram, Kemendiknas (2012) antara lain mengemukakan langkah-langkah pelaksanaan penanaman nilai-nilai karakter dalam pembelajaran.

a. Menggali pemahaman anak untuk tiap-tiap nilai karakter. Kegiatan ini bisa dilakukan melalui bercerita dan dialog yang dipandu oleh guru. Misalnya untuk tema tanaman, guru dapat mengajukan pertanyaan terbuka tentang karakter yang bertanggung jawab dalam memelihara tanaman. Contoh pertanyaan guru, "Mengapa kita harus bertanggung jawab memelihara tanaman? " atau "Bagaimana cara kita bertanggung jawab terhadap tanaman?" Setiap anak dapat memberi jawaban yang berbeda. Semua pendapat anak dihargai karena itu mencerminkan pemahaman mereka.

b. Membangun penghayatan anak dengan melibatkan emosinya untuk menyadari pentingnya menerapkan nilai karakter (bertanggung jawab). Proses ini dibangun juga melalui pertanyaan terbuka atau melalui pengamatan terhadap situasi dan kondisi yang ada di sekitar lembaga PAUD. Misalnya setelah bercerita dan berdialog tentang karakter tanggung awab terhadap tanaman, guru dapat mengajak anak berkeliling lembaga PAUD untuk bereksplorasi seputar tanaman dan mengamati perbedaan tanaman yang layu dan segar. Kemudian guru mengajukan pertanyaan, "Mengapa ada tanaman yang layu dan segar?", atau "Bagaimana rasanya bila kita menjadi tanaman yang layu tersebut?", atau "Apa yang harus kita lakukan agar tanaman tidak layu?"

c. Mengajak anak untuk bersama-sama melakukan nilai-nilai karakter yang diceritakan. Misalnya setelah anak bereksplorasi dan terdorong melakukan karakter tanggung jawab terhadap tanaman, maka guru memberi kesempatan kepada anak untuk melaksanakan karakter tanggung jawab terhadap tanaman sesuai keinginan dan kemampuan anak.

d. Ketercapaian tahapan perkembangan anak didik. Dalam hal ini anak diminta untuk menceritakan kegiatan dan perasaannya setelah melakukan kegiatan. Guru dapat memberikan penguatan dan pujian serta sentuhan kasih sayang terhadap apa yang direfleksikan anak, misalnya dengan mengatakan, "Terimakasih, sudah bertanggung jawab untuk menyiram tanaman."

Melalui langkah-langkah di atas, berarti satu nilai karakter ditanamkan pada anak secara berkelanjutan, dan konsisten, sehingga nilai karakter tersebut menjadi melekat pada diri anak. Itu artinya menggambarkan bahwa dalam membuat rencana pelaksanaan pembelajaran harian guru harus focus pada satu nilai karakter yang dirancang penananmannya melalui berbagai aktivitas yang melibatkan anak dalam menerapkan nilai karakter secara berkelanjutan dan indicator ketercapaiannya dirancang secara eksplisit.

\section{Metode Penelitian}

Penelitian ini merupakan penelitian kualitatif, yang merupakan studi pendahuluan, untuk mendapatkan informasi tentang perencanaan pendidikan karakter pada kurikulum pendidikan anak usia dini level kelas. Teknik pengumpulan data, menggunakan studi dokumentasi dan studi literatur. Dalam studi dokumen, digunakan dokumen yang menjadi focus kajian adalah dokumen kurikulum khususnya dokumen yang dikembangkan oleh para guru anak usia dini, yaitu berupa Rencana Pelaksanaan Pembelajaran (RPPH). Sampel penelitian 
sebanyak 20 dokumen RPPH, yang disusun oleh para guru yang bertugas di Taman Kanak-kanak yang ada di Kota Bandung. Sementara studi literature menelusuri beberapa situs di internet terkait dengan pengembangan pendidikan karakter pada kurikulum lembaga lain. Hal ini dilakukan untuk menambah khasanah wawasan pada penelitian selanjutnya dalam pengembangan pendidikan karakter dalam kurikulum pendidikan anak usia dini.

\section{Hasil Penelitian}

Hasil studi dokumen RPPH

Dokumen rencana pelaksanaan pembelajaran harian (RPPH) yang disusun oleh guru anak usia dini, pada umumnya disusun dalam bentuk format yang hampir sama. Setiap format rencana pelaksanaan pembelajaran memuat: identitas RPPH, dan selanjutnya dikembangkan format, dimulai dengan kolom nilai-nilai karakter, indicator, kegiatan pembelajaran yang meliputi tahap: pembukaan, inti, dan penutup, metode pembelajaran, media dan sumber, dan teknik penilaian.

Dari 20 dokumen RPPH yang dibuat oleh para guru anak usia dini. Pada umumnya sudah mencantumkan nilai-nilai karakter yang akan ditanamkan terhadap anak. Nilai-nilai karakter yang dikembangkannya ada yang lebih mengarah pada pembiasaan, dan ada pula yang dikembangkan untuk kegiatan inti pembelajaran. Khususnya dalam kegiatan inti pembelajaran, secara rinci dari 20 RPPH dapat dikemukakan sebagai berikut. Untuk kemudahan dalam mendeskripsikan data berikut ini dikemukakan dalam bentuk grafik.

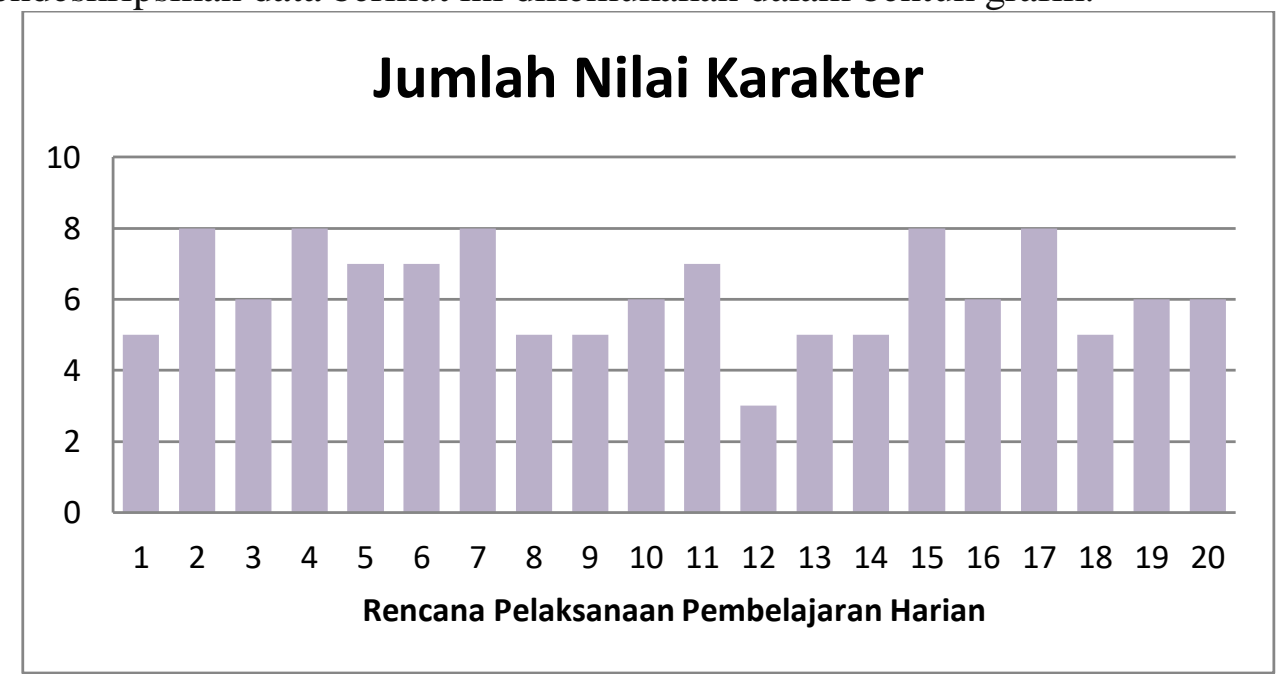

Grafik: Nilai-nilai karakter dalam RPPH

Grafik di atas menggambarkan bahwa setiap guru (20 orang) mencantumkan nilai-nilai karakter dalam RPPH sangat beragam, baik dilihat dari jumlah dan nilai karakter yang diprogramkannya. Paling sedikit dalam RPPH khususnya dalam kegiatan inti pembelajaran, guru anak usia dini mencantumkan tiga nilai karakter, dan paling banyak sampai delapan nilai karakter.

Dari hasil penelusuran lebih lanjut, nilai-nilai karakter apa yang paling banyak dikembangkan oleh guru, dapat dilihat pada grafik berikut ini 


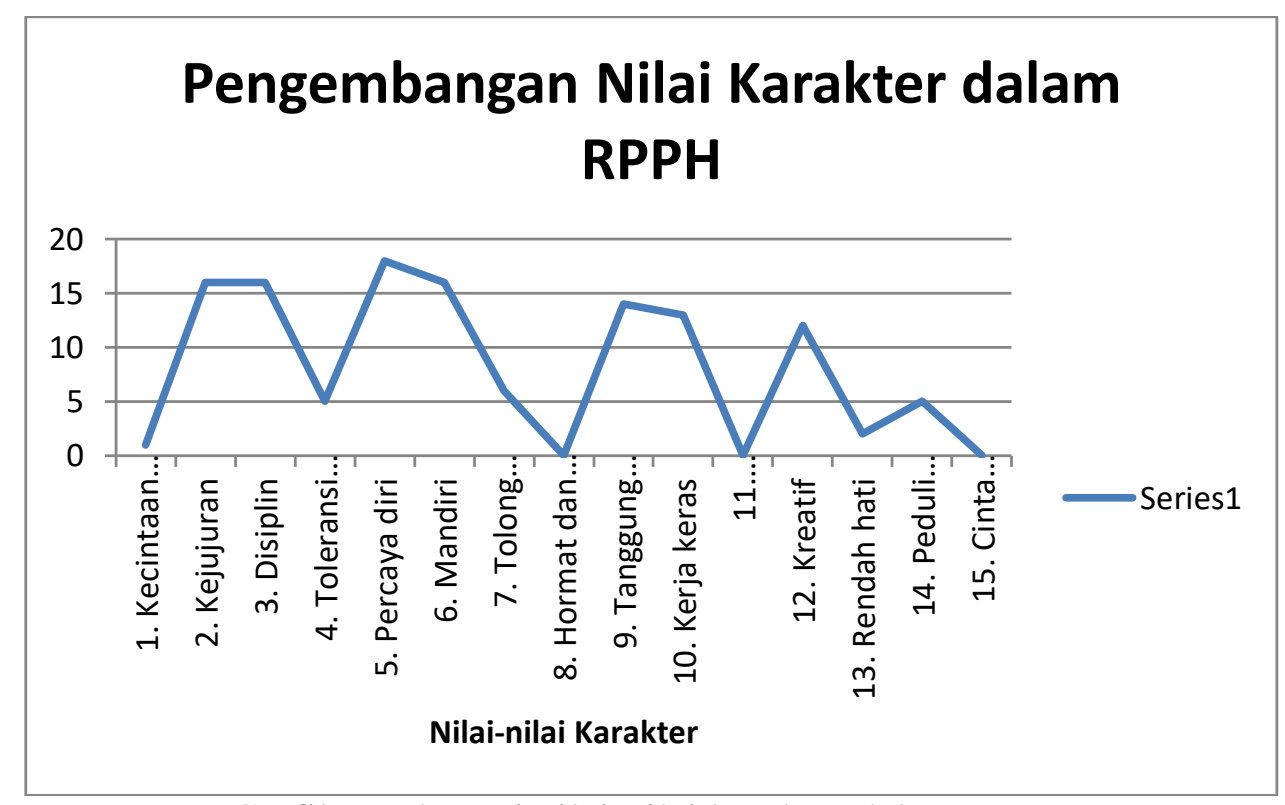

Grafik: Prekuensi nilai-nilai karakter dalam RPPH

Dari grafik di atas, dari 20 RPPH, nilai-nilai karakter yang paling banyak ditetapkan oleh guru secara urut di antaranya membangun nilai karakter: percaya diri, kejujuran, disiplin, mandiri, tanggung jawab, kerja keras, dan kreatif. Untuk nilai karakter yang lainnya, tidak berarti tidak dikembangkan, tetapi nilai-nilai karakter seperti kecintaan terhadap Tuhan YME, toleransi, hormat dan santun, dan sebagainya dikembangkan dalam program pembiasaan.

Dari telaah lebih lanjut dari sekian banyak nlai-nilai karakter yang dikembangkan, tidak terdapat rencana untuk penilaiannya yang secara spesifik menggambarkan setiap indicator keberhasilan dalam penanaman nilai-nilai karakter tersebut. Teknik penilaian yang ada masih bersifat umum, maksudnya lebih mengutamakan keberhasilan anak dalam aktivitas belajar, tetapi indikatornya belum dijabarkan.

\section{B. PEMBAHASAN}

Menyikapi cara-cara guru anak usia dini dalam menentukan nilai-nilai karakter yang pada umumnya dalam setiap rencana pelaksanaan pembelajaran harian meliputi beberapa nilai karakter bahkan sampai terdapat delapan nilai karakter yang harus dikembangkan dalam satu hari, sangat berbeda dengan hasil studi literature. Beberapa arahan dalam menentukan nilai-nilai karakter sebagaimana dikemukakan berikut ini.

1. DePorter, B. dkk. (2005) mengemukakan terdapat delapan kunci nilai karakter yang membuat anak didik menjadi excellence. Untuk membangun kedelapan kunci nilai karakter tersebut, guru harus memfokuskan pada satu nilai karakter untuk stiap bulannya, yang diintegrasikan ke dalam kurikulum dan pembelajaran melalui berbagai cara, seperti melalui berbagai tugas yang harus dikerjakan oleh anak, termasuk tips dalam menghadapi tes.

2. Education World (2015) mengemukakan bahwa "The Cleveland County Schools of North Carolina recommend emphasizing one trait of good 
character each month, with bulletin boards, writing assignments, and morning announcements. Students may pen slogans about the trait of the month, and a special section of the library might be designed to offer students easy access to the biographies and other stories of people who exemplify the best of each trait".

3. New Beginnings Academy tidak hanya mendidik anak dalam mata pelajaran akademik, tapi pendidikan karakter juga. Setiap bulan, anak fokus pada belajar "megaskill" di kelas dan selama mengikuti keseluruhan program sekolah. Anak yang telah menunjukkan perilaku teladan dihargai dan diberi penghargaan pada setiap hari jumat Setiap minggu, guru memilih salah satu anak dari kelas mereka yang telah menunjukkan sifat karakter bulanan untuk merayakannya. Anak ini dipanggil ke depan kelas dan mendapat tepuk tangan dan sorak-sorai, karena mereka dihargai untuk menjadi warga negara yang positif.

Contoh monthly megaskills:

- Respect - Aug/Sept;

- Responsibility - Oct;

- Caring/Compassion-Nov/Dec;

- Positive Attitude - Jan;

- Honesty - Feb;

- Cooperation - March;

- Perseverance - April;

- Wise Choices - May/June

(http://www.newbeginningsacademy.org/\#!monthly-mega-skills/ccr).

4. St. Mel School yang berada di Fair Oaks, California. Sebagai sekolah Katolik yang terdiri dari TK, SD, sampai SMP. Sekolah ini mengembangkan pendidikan karakter dengan mengacu pada nilai-nilai karakter Megaskills sebagaimana dikembangkan oleh Rich (2008). Program ekstensi sekolah ini di antaranya memperkuat harapan belajar anak di sekolah melalui program megaskills. Megaskills adalah nilai-nilai, kemampuan, dan mesin penggerak dalam belajar yang menentukan keberhasilan baik di sekolah maupun dalam kehidupan. Megaskills sangat penting, yang dapat diajarkan dan dipelajari. Megaskills bukan untuk mendapatkan "A" pada tes hari esok, tetapi ini tentang mendapatkan "A" untuk kehidupan. Dalam mengembangkan programnya, Each month Extension will highlight and focus on one Mega Skill:

- September: Responsibility, doing what's right

- October: Teamwork, working with others

- November: Confidence, feeling able to do it

- December: Motivation, wanting to do it

- January: Initiative, moving into action

- February: Caring, showing concern for others

- March: Problem Solving, putting what you know and what you can do into action

- April: Perseverance, completing what you start 
- May: Effort \& Growth, being willing to work hard

Guru berkerja sama dengan staf sekolah dalam mengamati perkembangan nilai-nilai megaskills tersebut. Pada akhir setiap bulan bagi anak yang berhasil akan mendapatkan hadiah. (http://www.stmelschool.org/home/extension/the_mega_skills_program)

Character is the personality inherent in a person (Kamaruddin, 2012). Program pengembangan nilai-nilai megaskills, pada era globalisasi harus menjadi prioritas utama (McElmeel, 2002; Dimerman, 2009). Kurikulum sebagai jantungnya pendidikan (Null, 2011), maka dari itu, agar jelas arah pengembangan nilai-nilai karakternya, harus secara eksplisit dituangkan secara terprogram dan berkelanjutan dalam setiap dokumen kurikulum (Aziz. 2011;Kamaruddin, 2012; Almerico, 2014). Tepatnya dokumen kurikulum harus menggambarkan suatu harapan yang jelas, baik dalam upaya keberhasilan secara akademik (tingkat pencapaian perkembangan anak) dan dalam membangun karakter anak (Trilling \& Fadel, 2009; Jackman, 2012; Rich, 2008; Null, 2011).

Untuk itu, karakter individu anak tidak dapat dibentuk hanya melalui satu atau dua kegiatan saja, melainkan harus ditanamkan secara berkelanjutan, dan konsisten. Dengan demikian, harus disiapkan melalui rancangan program pembangunan karakter yang terintegrasi dalam kurikulum dan pembelajaran secara berkelanjutan (Kamaruddin, 2012). Untuk itu, pendidik harus menemukan cara untuk menanamkan pembentukan karakter dalam kurikulum dan pembelajaran (Almerico,2014; Aziz., \& Ahmad, 2012).

\section{PENUTUP}

Pengembangan pendidikan karakter dalam kurikulum pendidikan anak usia dini, yang dikembangkan oleh guru terutama dalam perencanaan pelaksanaan pembelajaran harian, sangat variatif dan guru merencanakan penanaman nilai-nilai karakter dalam satu harinya paling sedikit tiga nilai karakter dan sampai yang paling banyak delapan nilai karakter. Sementara dari hasil studi literature dari beberapa situs di internet, pengembangan nilai karakter dalam kurikulum dan pembelajaran secara focus, konsisiten, dan berkelanjutan satu nilai karakter untuk satu bulan sampai nilai karakter tersebut dapat melekat pada diri anak. Bagi anak yang sudah berhasil memiliki nilai karakter tersebut, baik sekolah maupun guru memberikan penghargaan atas keberhasilannya.

\section{DAFTAR PUSTAKA}

Adeyemi, M. B., Moumakwa, T. V., \& Adeyemi, D. A. (2009). Teaching Character Education Across the Curriculum and the Role of Stakeholders at the Junior Secondary Level in Botswana. Stud Home Comm Sci: 3(2):97-105.

Almerico,G. M. (2014). Building character through literacy with children's literature. Research in Higher Education Journal Volume 26 pp. 1-13 
Aziz. H. A. (2011). Pendidikan karakter berpusat pada hati: Akhlak mulia pondasi membangun karakter bangsa. Jakarta: Al-Mawardi Prima.

Aziz, A. A., \& Ahmad, A. S. (2012) Low cost flats outdoor space as children social environment. Procedia - Social and Behavioral Sciences 38 ( 2012 ) 243 - 252. Published by Elsevier.

DePorter, B. dkk. (2005). School character education program. http://8keys.org/school_program.aspx

Dimerman, S. (2009). Character is the key : How to unlock the best in our children and ourselves. Canada: John Wiley \& Sons Canada, Ltd.

Education World (2015) Twenty-Five Activities for Building Student Character, School "Community". http://www.educationworld.com/help/about.shtml

Hooks, L. M., Little, C. S., Marshall, B. J. \& Brown, G. (2006). Accountability for Quality: One State's Experience in Improving Practice. Early Childhood Education Journal 5(399), 399-403.

Jackman, H. L. (2012). Early education curriculum: A child's connection to the world. United States of America: Wadsworth, Cengage Learning.

Kamaruddin, S.A. (2012). Character education and students social behavior. Journal of Education and Learning. Vol.6 (4) pp. 223-230.

Kemendiknas. (2010). Kerangka acuan pendidikan karakter. Jakarta: Kemendiknas; Direktorat Ketenagaan; Direktorat Jenderal Pendidikan Tinggi; Kemetrian Pendidikan Nasional.

Kemendiknas (2012). Pedoman pendidikan karakter pada pendidikan anak usia dini. Jakarta: Direktorat Pembinaan Pendidikan Anak Usia Dini; Direktorat Jenderal Pendidikan Anak Usia Dini, NonFormal, dan Informal; Kementerian Pendidikan Nasional

Lickona, T. (2004). Character matters: How to help our children develop good judgment, integrity and other essential virtues. New York: A Touchstone Book, Published by Simon \& Schuter.

McElmeel, S. L. (2002). Character education: A book guide for teachers, librarians, and parents. United States of America: Libraries Unlimited Teacher Ideas Press A Division of Greenwood Publishing Group, Inc.

Null, W. (2011). Curriculum: From theory to practice. United States of America: Rowman \& Littlefield Publishers, Inc.

New Beginnings Academy (http://www.newbeginningsacademy.org/\#!monthlymega- skills/ccr)

Priyatni, E. T. (2013). Internalisasi karakter percaya diri dengan teknik scaffolding. Jurnal Pendidikan Karakter, Tahun III, Nomor 2, 10 (164173).

Rich, D. (2008). MegaSkills: Building our children's character and achievement for school and life. Naperville, Illinois: Sourcebooks, Inc.

Stevenson, N. (2006). Young person's character education handbook. United States of America: JIST Publishing, Inc.

St. Mel's Catholic School http://www.stmelschool.org/academics/kindergarten 
Trilling, B. and Fadel, C. (2009). 21st century skills: Learning for life in our times.

United States of America: Jossey-Bass

http://www.stmelschool.org/home/extension/the mega_skills_program

http://www.newbeginningsacademy.org/\#!monthly-mega-skills/ccr 